\title{
Processos de significação pela leitura e escrita: jogo, matemática e linguagem
}

\author{
Cidinéia da Costa Luvison \\ Mestre, USF/SP \\ cidineiadacosta.luvison@gmail.com
}

\section{Regina Célia Grando}

Professora, USF/SP

regina.grando@saofrancisco.edu.br

\section{Resumo}

O texto diz respeito a uma pesquisa que buscou investigar como os conhecimentos matemáticos - explorados em um contexto de leitura e produção escrita em situações de jogo, na perspectiva da resolução de problemas - são mobilizados e (re)significados por alunos de um $5^{\circ}$. ano do Ensino Fundamental. Os dados foram produzidos a partir de registros dos alunos em diferentes gêneros textuais e audiogravação dos momentos de resolução de problemas a partir do jogo e da socialização. Foi possível constatar que, os alunos apropriam-se da linguagem e dos conceitos matemáticos, quando elucidados por meio de um contexto de investigações, em que a inferência, o dialogismo e a relação leitor-autor ajudam a constituir e a desenvolver cada sujeito.

Palavras-chave: Gêneros textuais. Jogos. Anos iniciais do Ensino Fundamental.

\section{Processes of meaning for reading and writing: game, mathematics and language}

\begin{abstract}
The text refers to research that investigates how mathematical knowledge - explored in the context of reading and writing in game situations from the perspective of problem solving - are mobilized and (re) signified by students from a 5 grade of elementary school. It was developed a sequence of tasks with games from the perspective of problem solving. The data were produced from student records in different text genres, audio recording of the moments of problem solving from the play and socialization. It was found that the students are appropriating the language and mathematical concepts, as elucidated by a research context, in which the inference, dialogue and reader-author relationship help establish and develop each individual who.
\end{abstract}

Keywords: Text genres. Games. Elementary school. 


\section{Introdução}

O presente trabalho se refere a um recorte de uma pesquisa que esteve pautada na interrelação de diferentes linguagens em aulas de Matemática, em que destacamos três vertentes histórico-culturais: jogo; leitura e escrita (comunicação matemática, apropriação da linguagem e desenvolvimento humano) e resolução de problemas em Matemática escolar.

A partir do entrecruzamento dessas três vertentes, o objetivo da pesquisa foi investigar como os conhecimentos matemáticos são mobilizados e (re)significados, quando explorados em um contexto de leitura e produção escrita em situações de jogo, na perspectiva da resolução de problemas por crianças do $5^{\circ}$. ano do Ensino Fundamental ( 9 a 10 anos). A produção dos dados ocorreu no ano letivo de 2009, com 23 alunos de uma escola pública municipal no interior de São Paulo. A pesquisadora estabeleceu uma parceria com a professora de sala de aula e desenvolveu uma sequência de tarefas, envolvendo jogos e diferentes gêneros textuais nas aulas de matemática.

Dentre a sequência de tarefas desenvolvidas, selecionamos para esse texto, as do jogo $K a l a h^{1}$, com o enfoque na leitura e na escrita a partir de diferentes gêneros textuais. Partimos do pressuposto de que o jogo pode propiciar o acesso a diferentes leituras e, consequentemente, à apropriação de linguagens - através da leitura das regras do jogo, de situações problema de jogo e suas relações com os gêneros textuais - estabelecendo um conjunto de significações. Com relação aos conteúdos matemáticos, o jogo kalah foi proposto com o objetivo de se desenvolver um modo de pensar matematicamente que envolve o levantamento de hipóteses, as implicações lógicas "se...então", a resolução de problemas, a verificação de regularidades e a análise de jogadas.

\section{Ler e escrever: um processo de dialogismo e inferência}

Ler, muito mais do que decodificar palavras e frases, encontra sua máxima expressão na comunicação e na reflexão. Através das palavras, é possível caminhar em busca de novas informações, em que não existe fim, mas recomeço; em que, constantemente, as palavras, as imagens, os textos possibilitam-nos uma relação de busca de novos significados.

1 Kalah: Distribui-se 3 sementes em cada espaço e no meio deverá conter 4 sementes. Os Kalahs das laterais deverão ficar vazios. Cada jogador fará a jogada na sua vez, distribuindo-as uma a uma a sua direita. Ao passar pelo seu Kalah, o jogador deve deixar uma semente e continuar a distribuição. Caso a semente seja colocada no Kalah do próprio jogador, este poderá jogar novamente. Se a ultima semente colocada, cair em uma casa vazia, do seu lado do tabuleiro, as sementes do adversário, diretamente a frente, será capturada. $\mathrm{O}$ jogo termina quando um dos jogadores não possuírem mais sementes a movimentar. 
Pela leitura é possível alçar vôos, mas ela não se configura como certa, verdadeira ou única, pois as palavras e os textos adquirem amplitude a todo instante. Em cada sujeito, há, do que se lê, uma compreensão e um significado diferente, não há limites para essa multiplicidade. Decodificar, simplesmente, seria não viver esse movimento. É como se partíssemos para uma viagem sem ao menos vislumbrar o que a paisagem nos oferece, negando a existência da observação vivida e das raízes culturais que constituem o sujeito enquanto leitor.

Assim, muito mais do que compreender a escrita gráfica, a riqueza da leitura está atrelada às relações que são atribuídas em sua prática. Dessa maneira, ler está além de assimilar conteúdos disciplinares: é um instante de "dar voz" (sujeito-texto-comunicação) ao que está escrito.

$\mathrm{O}$ processo entre o texto e o leitor possibilita constantemente relações de inferência. Para Koch (2003), o sentido não está no texto, mas constrói-se a partir dele, no curso de uma interação. É necessário afirmar que essa ação não é de passividade ou de mera receptividade, mas o texto ganha forma e coloca-se por um processo dialógico de conhecimento.

Pautando-nos em Bakhtin (2000), entendemos o dialogismo como a relação estabelecida entre os sujeitos, na interação verbal, mas, de certa forma, também na interação escrita. O dialogismo não possui suas raízes na individualidade, mas, sim, entre os sujeitos, os textos e seus escritos.

Assim, ao trazer essa relação para a escrita, sua compreensão é encontrada na interação escritor-leitor, pois, ao escrever, existe a preocupação com o outro que também irá estabelecer outras relações, que não são estáticas. De acordo com Brandão (2001, p.287-288),

ler torna-se, então, uma atividade de co-enunciação, o diálogo que o autor trava com leitor possível, cujos movimentos ele antecipa no processo de geração do texto e também como atividade de atribuição de sentido ao texto promovido pelo leitor no ato da leitura. Esta concepção de produção da escrita e da leitura insere-se numa concepção de linguagem enquanto fenômeno heterogêneo, polifônico; linguagem concebida enquanto signo e não sinal.

A partir disso, pensamos que a leitura tem suas bases na transformação. Ao ler e compreender, estabelecendo analogias, relações, comparações, enfim, inferindo, o leitor transforma-se o tempo todo; coloca-se na leitura a partir do momento em que esta lhe traz significados, lhe traz a proximidade com a sua própria vida, e esse movimento pode ser propiciado durante as aulas de Matemática em que através do 
jogo, o aluno entra em contato com diferentes leituras, durante a leitura da regra, na produção de estratégias e na reflexão de cada um dos movimentos do jogador.

Ora, a leitura e a escrita são indissociáveis, na prática. Ao escrever, existe uma relação entre os pensamentos, as hipóteses e as conclusões do escritor, ou seja, existe uma relação dialógica, pois não há como escrever e não pensar no leitor do seu próprio texto.

O momento de ler e o de escrever são únicos. Ao escrever, o autor-leitor mostra o caminho percorrido, evidencia seus valores, suas crenças, suas construções, suas hipóteses e conjecturas, ele se coloca no texto. A todo o instante nos são oferecidas, pela multiplicidade de linguagens, novas formas de ler e compreender cada contexto, e a escola vem contribuir com essas múltiplas linguagens. Cabe a ela proporcionar momentos nos quais o trabalho com diferentes gêneros textuais seja assegurado por meio de um ambiente no qual a inferência e a discussão sejam aliadas às investigações, em que o texto se torna um problema a ser resolvido.

Acredita-se que uma prática possível de que o aluno seja capaz de se expressar por meio de diferentes linguagens seja por meio de jogos, pautados em uma perspectiva de resolução de problemas.

Nas aulas de Matemática, o professor precisa ir além do "jogo pelo jogo", a fim de dar condições para que este seja explorado com um novo olhar na sala de aula, o que Grando (2000) chamou de "momentos de jogo". Nesses momentos, os alunos terão condições de refletir, comunicar, argumentar, levantar hipóteses, conjecturas e validar suas análises, o que contribui com dois aspectos: primeiro, a apropriação da linguagem matemática, principalmente em relação à leitura desses escritos; e segundo, a importância do registro nesse processo.

Enfatizamos que ambos, leitura e escrita, trazem a possibilidade de pensar sobre os momentos de jogo como uma relação importante tanto para a apropriação da linguagem matemática, quanto para a compreensão de conceitos matemáticos, também possibilitados pela dialogicidade entre leitura e escrita.

No quadro a seguir, explicitaremos os momentos de jogo abordados por Grando (2000) e a releitura que fizemos a partir da perspectiva da leitura, da escrita e da resolução de problemas.

\begin{tabular}{lll}
\hline $\begin{array}{l}\text { MOMENTOS DE JOGO } \\
\text { (GRANDO, 2000, 2004) }\end{array}$ & $\begin{array}{l}\text { MOVIMENTOS DO } \\
\text { JOGO }\end{array}$ & $\begin{array}{l}\text { INTERVENÇÃO PEDAGÓGICA } \\
\text { (Ler, escrever e comunicar) }\end{array}$ \\
\hline 1) Familiarização & 1) Conhecendo o jogo e a & $\begin{array}{l}\text { Resgate histórico: relação entre tempo, } \\
\text { cultura }\end{array}$ \\
& & $\begin{array}{l}\text { história, cultura e material do jogo } \\
\text { (BROUGĖRE, 1998). }\end{array}$ \\
\hline
\end{tabular}




\begin{tabular}{|c|c|c|}
\hline $\begin{array}{l}\text { 2) Reconhecimento das } \\
\text { regras }\end{array}$ & $\begin{array}{l}\text { 2) Fazendo contato com } \\
\text { as regras }\end{array}$ & $\begin{array}{l}\text { Leitura da regra: constante movimento } \\
\text { de inferência, reconhecimento do } \\
\text { gênero, levantamento de hipóteses, } \\
\text { reflexão, analogias e apropriação da } \\
\text { linguagem (BAKHTIN, 1999, 2000; } \\
\text { SCHNEUWLY; DOLZ, 1999, 2003). }\end{array}$ \\
\hline $\begin{array}{l}\text { 3) Jogar para garantir as } \\
\text { regras - "jogo pelo jogo" }\end{array}$ & $\begin{array}{l}\text { 3) Compreendendo a regra } \\
\text { do jogo }\end{array}$ & $\begin{array}{l}\text { (Re)significação da leitura: } \\
\text { compreensão, apropriação dos escritos } \\
\text { da regra, estabelecimento de relações } \\
\text { com as jogadas (GRANDO, 2000). }\end{array}$ \\
\hline $\begin{array}{l}\text { 4) Intervenção pedagógica } \\
\text { verbal }\end{array}$ & $\begin{array}{l}\text { 4) Refletindo sobre as } \\
\text { jogadas }\end{array}$ & $\begin{array}{l}\text { Pela intervenção do professor, é } \\
\text { possível presenciar a comunicação de } \\
\text { diferentes vozes, que são materializadas } \\
\text { no momento da escrita e durante as } \\
\text { partidas do jogo (GRANDO, 2000). }\end{array}$ \\
\hline 5) Registro do jogo & $\begin{array}{l}\text { 5)Registrando, } \\
\text { compreendendo, } \\
\text { significando }\end{array}$ & $\begin{array}{l}\text { Sistematização das jogadas: através } \\
\text { do registro livre e com leitor externo, } \\
\text { é possível analisar, reescrever e } \\
\text { reformular as estratégias do jogo, } \\
\text { apropriando-se da linguagem e dos } \\
\text { conceitos matemáticos (POWELL; } \\
\text { BAIRRAL, 2006). }\end{array}$ \\
\hline 6) Intervenção escrita & 6) Resolvendo problemas & $\begin{array}{l}\text { Análise das jogadas: ler, inferir, refletir, } \\
\text { analisar, registrar, levantar hipóteses, } \\
\text { reescrever e validar (ERNEST, 1998; } \\
\text { GRANDO, 2000) }\end{array}$ \\
\hline \multirow[t]{3}{*}{$\begin{array}{l}\text { 7) Volta ao jogo: "jogar } \\
\text { com competência" }\end{array}$} & $\begin{array}{l}\text { 7) Socializando e trocando } \\
\text { experiências }\end{array}$ & $\begin{array}{l}\text { A comunicação de ideias ocorre em dois } \\
\text { momentos: enunciação e autorreflexão. } \\
\text { Nesse instante, os alunos refletem, } \\
\text { comparam e releem seus escritos e } \\
\text { discursos (BAKHTIN, 1999, 2000; } \\
\text { PIMM, 1999; POWELL; BAIRRAL, } \\
\text { 2006). }\end{array}$ \\
\hline & 8) Atribuindo significados & $\begin{array}{l}\text { A análise, a comunicação, a reflexão em } \\
\text { torno das jogadas possibilitam retornar } \\
\text { à situação real de jogo, propondo um } \\
\text { novo significado ao jogo(GRANDO, } \\
2000 \text { ). }\end{array}$ \\
\hline & 9) Mobilizando o professor & $\begin{array}{l}\text { Análise do percurso: é realizada } \\
\text { pelo professor e constitui-se de dois } \\
\text { momentos: a volta ao jogo e a análise da } \\
\text { ação e dos registros (GRANDO, 1995, } \\
\text { 2000). }\end{array}$ \\
\hline
\end{tabular}


Entendemos que esse quadro possibilita sistematizar as relações que se podem estabelecer entre jogo, linguagem e o pensamento matemático, uma vez que nos momentos do jogo, a linguagem, por meio de diferentes gêneros textuais, expressa uma significação possível para o que foi lido e escrito a partir da intervenção com o jogo e que manifesta as relações, sistematizações e produções matemáticas.

\section{Ler, escrever e jogar: uma relação entre diferentes linguagens}

Dialógica por natureza, a leitura e a escrita possibilitam ao sujeito refletir, rever posições, interrogar-se sobre determinados assuntos, mobilizar-se em torno de pensamentos, ações e impressões que se tenham da realidade. Nessa relação, a regra do jogo também é construída. Ler e compreender seu gênero textual, neste caso, instrucional, vivenciando seu estilo e o do próprio leitor, o uso de suas palavras e a função social a que ele se propõe, faz com que ler não seja um ato de isolamento, mas uma vivência e um momento de desenvolvimento de cada sujeito.

A partir dessa perspectiva, ler a regra torna-se, também, um problema a ser resolvido, instigando o leitor a buscar caminhos para iniciar as jogadas, inferir, discutir e vivenciar a escrita, levantando hipóteses, conjecturas, além de apropriar-se da linguagem matemática.

Partindo dessa ideia, de unir na pesquisa a circulação de diferentes linguagens e a compreensão e apropriação da linguagem matemática a partir de gêneros textuais colocamos os alunos do $5^{\circ}$ ano do Ensino Fundamental a refletir a partir da regra do jogo Kalah.

Para a leitura da regra procuramos deixar os alunos a vontade para decidir como fariam a compreensão dessa leitura. De modo geral, procuraram se organizar em grupos e buscar alternativas e possibilidades para compreender o texto e reportar-se ao jogo, inferindo sobre a leitura e dando significado a esse momento, já que o objetivo seria iniciar o jogo.

$\mathrm{Na}$ leitura do jogo foi possível evidenciar dois movimentos: o de inferência e o de comunicação, através do contato com as cinco primeiras regras do jogo.

Segundo as necessidades de cada grupo, os alunos realizaram a leitura e a releitura do texto, a fim de compreender alguns pontos que não ficaram claros no decorrer da leitura. Durante o momento de intervenção da pesquisadora, um dos grupos - o de Everton, Guilherme, Davi e Miguel $^{2}$ - demonstrou certa insegurança em relação ao início da distribuição das sementes. Um dos conflitos era em relação à regra número três, quanto à movimentação das peças e a sua distribuição pela direita.

2 Os nomes dos alunos envolvidos foram preservados, e foram adotados pseudônimos. 
Cid: Conseguiram distribuir as sementes no tabuleiro?

Everton: É assim, pega uma por uma e vai colocando em cada casinha (distribuindo pela esquerda). Assim, você escolhe a casinha que você quiser pôr. Cid: Mas qual das casinhas?

Everton: Assim, ó, uma aqui, outra aqui e outra aqui.

(3) (3) (4) (3) (3)

(B)

(3) (3) (4) (3) (3)

(Ele iniciou da quarta casa, e foi distribuindo: uma semente para a terceira, outra para segunda e a última na primeira, pela esquerda).

Guilherme: Não, não é assim, é para lá! (indicando pela direita)

Cid: Mas, está escrito na regra? É dessa forma?

Guilherme: É para escolher a casinha, a casinha que quiser.

Everton: Ah, Guilherme, tem que vir daqui (terceira casa, indo para direita) e não daqui (terceira casa indo para esquerda).

Davi: Espera ai, olha, escuta! "Cada jogador, na sua vez, escolhe uma casa do seu lado do tabuleiro, pega todas as sementes dessa casa e as distribui uma a uma em cada casa localizada a sua direita, sem pular nenhuma casa e nem colocar mais de uma semente em cada casa."

Everton: Ah! É isso mesmo, está certo, viu, agora são vocês.

Miguel: Vou começar... (O aluno iniciou a distribuição, e fez o primeiro ponto).

No decorrer do jogo o aluno Everton tinha em sua quarta casa cinco sementes; segundo seu raciocínio, ele pegaria todas as sementes e distribuiria uma na quinta casa e as quatro sementes restantes colocaria todas em seu kalah. Cid: A regra diz que, ao chegar no seu próprio kalah, as sementes que você tiver na mão deverá ser colocada no kalah?

Everton: Acho que não.

Cid: Que tal olhar novamente na regra?

É interessante perceber que, conforme os alunos vão retomando a leitura, discutindo, observando, fazendo tentativas, conseguem compreender de que forma o jogo é conduzido. 
Nesse movimento de ler, reler, antecipar e voltar ao jogo, a escrita começa a fazer sentido.

Outro momento importante foi a proposta de registro. Pela escrita, os alunos antecipam, explicitam suas posições, estratégias e validam algumas de suas ideias, atrelando as características do gênero textual e colocando-se enquanto autor e leitor de seu próprio texto, que será escrito para um outro. Assim, o sujeito mobilizará suas capacidades de linguagem.

Dessa forma, para que pudéssemos ter acesso às diferentes leituras e propostas de resolução para as situações-problema, durante a ação no jogo, propusemos para que os alunos escrevessem sobre suas reflexões, acreditando que tal atitude seria outro passo importante para as (re)significações sobre o jogo. Foi a partir dessa proposta que os alunos conseguiram refletir a partir do registro.

Porém, escrever pelo simples fato de transpor o que observaram durante o jogo "sufocaria" todo o contexto vivido pelos alunos até então. Para escrever, seria necessário trazer um movimento próximo a sua função social, colocar a relação leitura-escrita como mais uma ação a ser resolvida. Chamamos de registro com leitor externo a produção reflexiva do texto.

Através da produção escrita do gênero carta, com o jogo Kalah nosso objetivo seria observar os saberes e os conceitos matemáticos que seriam registrados sobre os momentos de jogo, juntamente com as análises e as estratégias que vinham sendo construídas.

Foi proposto aos alunos, uma troca de cartas, com uma leitora externa. Nesse caso, os alunos tinham como objetivo auxiliar uma jogadora (neste caso, a segunda autora desse texto e professora orientadora da pesquisa) que estava precisando de nossa ajuda, pois não conhecia todas as estratégias do jogo. Nessa situação imaginária criada para que os alunos escrevessem, foi dito que a leitora compreendia suas regras, toda a sua história, mas muitas estratégias ainda estavam por ser construídas.

Além disso, foi dito aos alunos que, o que mais a incomodava é que perdia todas as partidas para o seu marido, pois esse conhecia muito bem as estratégias. Assim, a escrita e leitura da carta tinha um objetivo explícito: ensinar estratégias a uma pessoa.

Dessa forma, foi possível envolver os alunos em uma situação imaginária, buscando estratégias para comunicar à leitora de cartas. Além disso, perceberam que havia algo importante a ser realizado, sentindo-se entusiasmados pela proposta, pois a escrita seria mediadora desse processo, já que para escrever algumas estratégias, teriam que refletir sobre suas próprias jogadas.

Para desenvolver essa atividade de produção da carta, tivemos a preocupação de enfocar algumas características do gênero, e ao mesmo tempo, explicitando o estilo de cada sujeito. Ao discutir sobre as características do gênero criamos condi- 
ções para que os alunos não só compreendessem a estrutura do texto, mas também, conseguissem visualizar para quem, para quê, sobre o quê e qual a função da escrita.

Durante o processo de escrita, em duplas, houve momentos importantes de discussão, em que foram evidenciadas algumas estratégias, de forma que os alunos se sentiram à vontade para expressar suas observações e construir novos pensamentos $\mathrm{e}$ hipóteses durante as intervenções realizadas pela jogadora na devolutiva das cartas.

Durante a escrita, conseguiram notar a diferença entre escrever uma regra e uma estratégia, tendo esses momentos sido subsidiados também pela volta ao jogo, a fim de refletir e analisar se eram realmente significativas. Na carta produzida foram destacados alguns pontos importantes em relação à regra, situações de jogo e as estratégias.

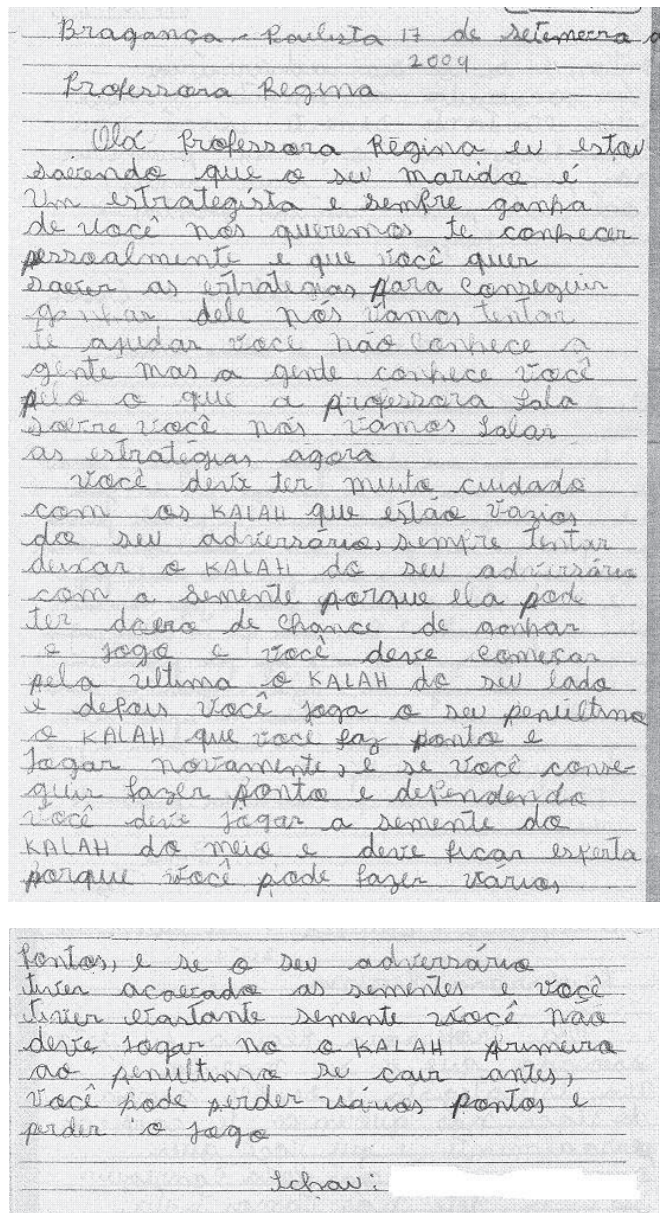

Diário de campo, 17/09/09. 
Através do registro, foi possível perceber a elaboração de alguns conceitos, por exemplo, a previsão/antecipação de jogadas e o raciocínio matemático, juntamente com seu desenvolvimento de espacialidade e noções de quantidade. Esses conceitos tornaram-se frequentes e contextualizados no jogo e no registro.

Ao estabelecer essa relação de busca de novos significados, através de uma atitude que não é de recepção, o conhecimento matemático escolar viabiliza a investigação e a elaboração de conceitos, que tem como objetivo um ambiente rico de aprendizagem, concebido através do jogo, da leitura e da escrita de diferentes gêneros.

Esse cenário não permite a presença restrita de perguntas e respostas, mas exige uma atitude que requer discussão e busca coletiva, que está além da manipulação de símbolos e regras, mas sim, por um processo dinâmico de diferentes leituras (leitura da regra de um jogo, leitura de situações-problema de jogo, etc.).

Como destacado por Schneuwly (2003), cada gênero se dá em função da temática e dos participantes envolvidos, nesse sentido, existe uma relação de "interconexação" entre o gênero e seu contexto, ou seja, "a ação discursiva, é, portanto, ao menos parcialmente, prefigurada pelos meios". (Idem, p. 28)

Destacamos ainda, que a devolutiva das cartas para os alunos, significou uma releitura de suas conclusões iniciais, colocando-os a repensar o jogo e sua própria escrita, o que esteve presente no segundo registro dos alunos.

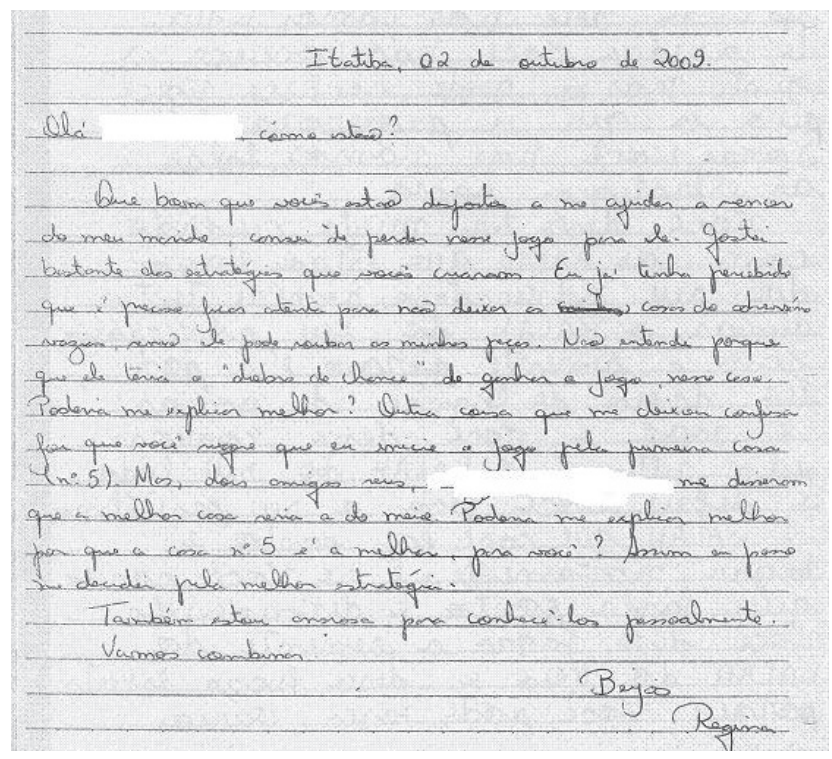

Diário de campo, 02/10/09. 
Como destacado, na intervenção escrita acima, os alunos são mobilizados, através da escrita do outro, a refletir sobre suas próprias posições e revê-las durante o jogo. A leitura tornou-se reflexiva, pois os alunos tiveram que voltar ao jogo, rever suas estratégias e pensamentos, jogar novamente e registrar. Para Powell e Bairral (2006), retomar seus escritos possibilita revisitar antigas concepções e modificá-las através de suas reflexões, reinterpretando e revisando suas interpretações, através de atitudes investigativas.

Pela intervenção escrita da leitora, foi possível para os alunos revisitar alguns conceitos matemáticos e ao mesmo tempo, pensar sobre a linguagem, como forma de comunicação, convencimento, reflexão e (re)significação.

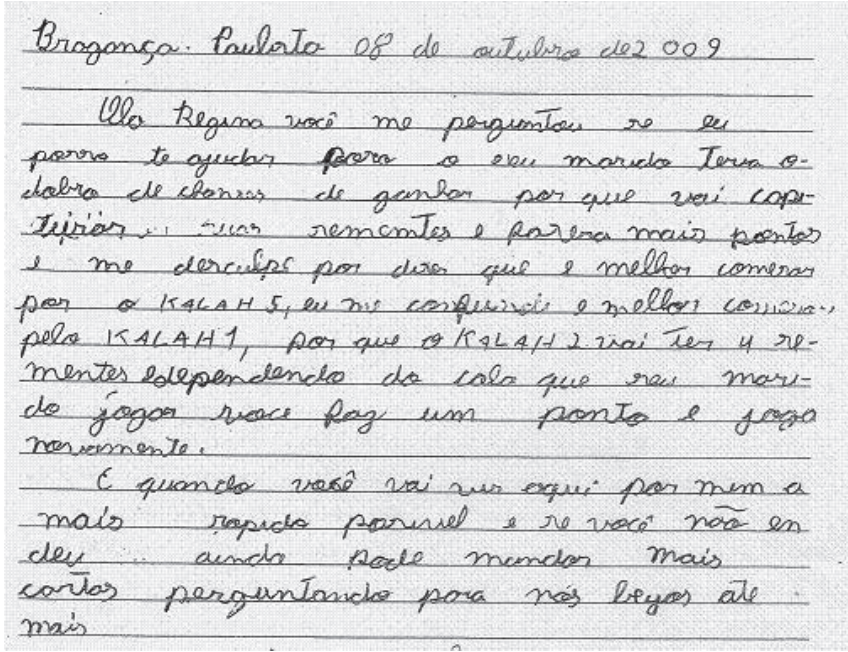

Diário de campo, 08/10/09.

À medida que os alunos realizam o processo de leitura, escrita e reescrita, diante de um contexto de jogo, vivenciado e construído com todo o grupo, a leitura e a linguagem matemática, gradualmente, vão sendo apropriadas por eles. Além disso, atrelar esse conjunto a função social faz com que os objetivos e as relações estabelecidas com a leitura sejam mais abrangentes.

Outro ponto a destacar é que durante o registro dos alunos, vemos a presença da apropriação da regra, quando menciona "jogar novamente", além da produção da estratégia e dos conceitos matemáticos, tão destacados pela antecipação da jogada, quando os alunos se referem "dependendo do kalah que seu marido jogar".

Muito mais do que ler e interpretar, o que observamos é que a linguagem está imersa na cultura e no desenvolvimento humano. Através das enunciações 
os sujeitos utilizam expressões, gêneros textuais para serem compreendidos nas relações sociais e nos escritos do jogo existe essa atitude do leitor, que se coloca e ao mesmo vive o texto, pois existe além da inferência, da mobilização, um sentido para o próprio sujeito, que se desloca a pensar sobre seus próprios escritos. Como mencionado por Dahlet (2001, p. 84)

[...] o fato de que o sujeito se constrói não só pela determinação do outro, mas pelo esforço para se diferenciar das formas desse outro que o reformula completamente. Portanto, é só retomando intensamente sua presença através das marcas de ruptura com o nós consensual que o antecede, que o eu torna possível o que dele se perceberá.

Entendemos que quando os alunos registram seus pensamentos, refletindo sobre suas jogadas e colocando-se no texto, a linguagem matemática se vê articulada à língua materna, pois não fazem dissociação nesses escritos, mas sim, realizam sua complementaridade.

Muito mais do que um contexto de formalização matemática, a linguagem torna-se próxima ao aluno, que se sente envolvido e mobilizado pela sua escrita, ou seja, assume uma postura de autor-leitor, autor-escritor e autor-criador.

De forma geral, quando há envolvimento com a linguagem matemática, significativamente, ou seja, de acordo com seu contexto, seu tempo e seu espaço, a sua formalização convive harmoniosamente, com a língua materna e dela se aproxima.

Essa aproximação entre as linguagens também estiveram presentes durante a resolução de situações-problema de jogo. Entendemos que trabalhar em uma perspectiva de resolução de problemas leva os alunos a pensar nas situações propostas no jogo, relacionando-as à linguagem matemática e aos conceitos que mobilizam nas jogadas.

A situação proposta tinha o objetivo de que os alunos refletissem sobre algumas jogadas e estratégias, mas, principalmente, o foco estava em observar como conduziam a leitura e a escrita dessas situações. Através da representação de uma jogada, os alunos realizaram algumas conclusões, lendo, escrevendo e reescrevendo sobre suas ideias. Na situação a seguir, as alunas Bárbara e Valéria demonstram a apropriação do jogo e de suas regras e, ao mesmo tempo, a produção de suas estratégias.

1) O jogo está como mostra a situação abaixo. Após observar, responda as questões a seguir: 


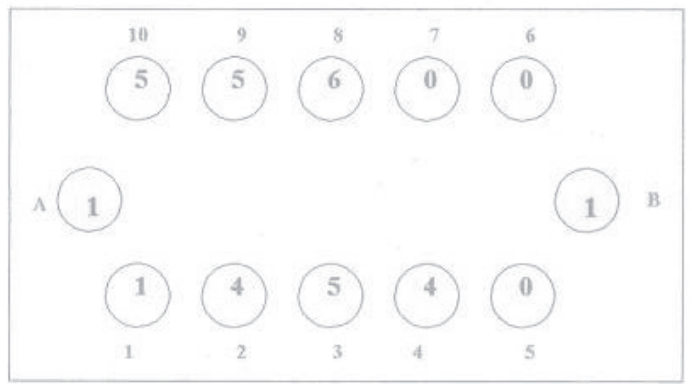

2) Se você fosse o jogador B, em qual casa mexeria? Por quê?

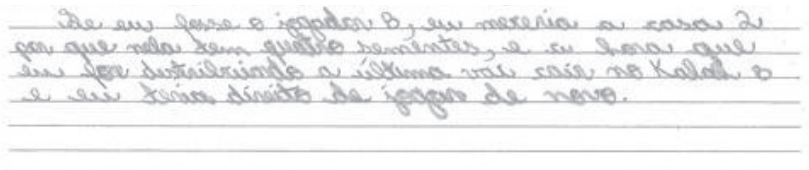

3) Após a primeira jogada, depois de escolher a casa, qual a próxima jogada que você faria? Por quê?

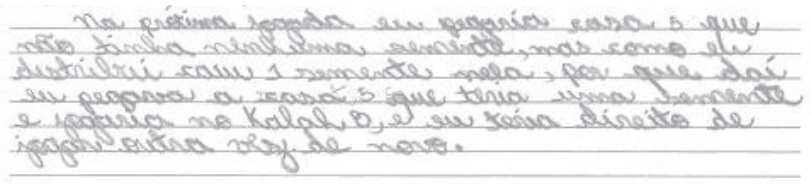

4) O jogador B teria a oportunidade de continuar com o jogo a seu favor?

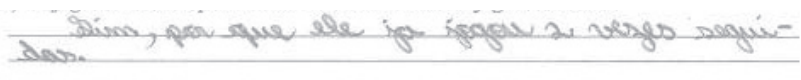

Diário de campo, dia 24/09/09.

É possível observar, nessa situação, que as alunas se apropriaram da regra e utilizaram em seus escritos essa linguagem, como "distribuindo", "direito de jogar de novo", "duas vezes seguidas", "a última vai cair"; enfim, expressões que estiveram presentes na leitura da regra, da troca de ideias entre os grupos, na intervenção da pesquisadora e que foram sendo significadas pelas alunas no registro escrito da situação de jogo. 
Além disso, mais dois elementos importantes fizeram-se presentes: o primeiro em relação à sequência de jogadas e o segundo acerca das estratégias produzidas no movimento de jogo. Ambos contribuíram para a compreensão do gênero textual, presente nos escritos do problema, além de mobilizar as alunas a sair da situação de jogo e analisar a partir de sua representação. Como destacado por Powell e Bairral (2006, p. 26), “a escrita força os interlocutores a refletir, diferentemente, sobre sua experiência matemática. Enquanto examinamos nossas produções, desenvolvemos nosso senso crítico. A escrita suporta atos de cognição e metacognição".

Dessa forma, ler a situação proposta encontra-se atrelado a uma linguagem produzida pelos alunos. Tais escritos, como: "em qual casa mexeria", "próxima jogada", "jogo a seu favor", são situações vivenciadas, verbalizadas e discutidas entre eles e, ao mesmo tempo, apropriadas a partir de uma relação de complementaridade e aprendizagem.

\section{Algumas reflexões}

No decorrer do artigo é possível observar através de todo o movimento realizado pelos alunos de leitura, escrita e comunicação que a linguagem está imersa em uma relação que transcende o ler, o escrever, o interpretar, o decifrar: faz-se pela relação entre os sujeitos, nos discursos proferidos e nas reflexões realizadas diante das ações cotidianas; ou seja, as ações de ler, escrever e jogar estão presentes na relação de si e do outro. Muito além de palavras e frases para serem decifradas e resolvidas, existe uma dinâmica que é vivenciada pelo próprio leitor-escritor, o qual evidencia, em seus escritos e em suas jogadas, seus desejos, sentimentos, impressões, seu inacabamento e seus traços culturais, já que a linguagem também se desenvolve na brincadeira, no jogar.

Entendemos que ao explorar a linguagem, estamos possibilitando aos alunos o acesso a especificidade da linguagem matemática e ao mesmo tempo, viabilizando o contato com a diversidade de gêneros textuais que estão presentes em nosso cotidiano e são utilizados como instrumentos de desenvolvimento e dizeres cotidianos no interior das relações sociais.

Ao escrever as cartas, evidenciamos a transformação ocorrida nesses sujeitos e a interlocução estabelecida entre os autores, que deslocaram os outros (leitores) a pensar reflexivamente sobre a temática do jogo e de suas estratégias.

Através da linguagem os alunos (re)significam o seu aprendizado constantemente, relacionando, levantando hipóteses, conjecturas e apropriando-se de novas linguagens e conceitos. Viver o movimento que a linguagem oferece, é trazer para as aulas de Matemática a contribuição de que o aluno, mediante a leitura, escrita, 
comunicação de ideias e sua apropriação, está se desenvolvendo, refletindo e ao mesmo tempo, transcendendo a visão absolutista da Matemática, pelas diferentes vozes que circulam na interlocução entre os sujeitos, viabilizando mais que o "fazer", um "dizer" repleto de significado.

\section{Referências}

BAKHTIN, M. (Volochinov). Marxismo e filosofia da linguagem: problemas fundamentais do método sociológico na ciência da linguagem. 9. ed. São Paulo: Hucitec, 1999.

BAKHTIN, M. Estética da criação verbal. São Paulo: Martins Fontes, 2000.

BRAIT, B. (Org.). Bakhtin, dialogismo e construção do sentido. Campinas: Editora da Unicamp, 2001.

BRANDÃO, H. H. N. Escrita, leitura e dialogicidade. In: BRAIT, Beth (Org.) Bakhtin, dialogismo e construção do sentido. Campinas: Editora da Unicamp, 2001.

BROUGÈRE, G. Jogo e Educação. Tradução Patrícia Chittoni Ramos. Porto Alegre: Artes Médicas, 1998.

DAHLET, P. Dialogização enunciativa e paisagens do sujeito. In: BRAIT, B. (Org.) Bakhtin, dialogismo e construção do sentido. Campinas: Editora da Unicamp, 2001 .

ERNEST, P. Investigações, resolução de problemas e Pedagogia. In: ABRANTES, P.; LEAL, L. C.; PONTE, J. P. (Org.) Investigar para aprender matemática: textos selecionados. Lisboa: Projeto MPT e APM, 1998. p. 25-48.

GRANDO, R. C. O jogo e suas possibilidades metodológicas no processo ensino-aprendizagem da matemática. Dissertação (Mestrado em Educação) - Universidade Estadual de Campinas, Campinas, São Paulo, 1995.

. O conhecimento matemático e o uso de jogos na sala de aula. Tese (Doutorado em Educação) - Universidade Estadual de Campinas, Campinas, São Paulo, 2000. 
KOCH, I. V. O texto e a construção dos sentidos. 6. ed. São Paulo: Contexto, 2003.

PIMM, D. EI lenguaje matemático en el aula. Madrid: Ediciones Morata, S.L., 1999.

POWELL, A.; BAIRRAL, M. A escrita e o pensamento matemático: interações e potencialidades. Campinas, SP: Papirus, 2006. (Coleção perspectivas em Educação Matemática).

SCHNEUWLY, B. Gêneros e tipos de discurso: considerações psicológicas e ontogenéticas. In: SCHNEUWLY, B.; DOLZ, J. Gêneros orais e escritos na escola. Campinas: Mercado de Letras, 2003.

Submetido em dezembro de 2011

Aprovado em abril de 2012 